\title{
ANALISIS KARAKTERISTIK SOSIAL EKONOMI PENYULUH DENGAN PELAKSANAAN PENYULUHAN DI KABUPATEN MINAHASA
}

\author{
Gabriella Mangare, B.F.J. Sondakh*, F.S. Oley, M.T. Massie \\ Fakultas Peternakan Universitas Sam Ratulangi Manado, 95115
}

\begin{abstract}
ABSTRAK
Petugas penyuluh lapangan mempunyai peranan strategis dalam meningkatkan kesejahteraan petani/peternak. Salah satu faktor yang berpengaruh terhadap keberhasilan penyuluh menjalankan tugasnya adalah keadaan latar belakang sosial ekonomi atau karakteristik sosial ekonomi dari setiap penyuluh. Namun demikian sejauhmana hubungan antara karakteristik sosial ekonomi dengan pelaksanaan penyuluhan di Kabupaten Minahasa belum diketahui. Berdasarkan permasalahan tersebut maka tujuan penelitian ini adalah untuk mengetahui hubungan karakteristik tersebut dengan pelaksanaan tugas penyuluh dengan baik. Penelitian ini menggunakan metode survey dalam pengumpulan data terhadap responden penyuluh dan dianalisis secara deskriptif. Data yang terkumpul disajikan dalam tabel silang antar variabel (pendidikan dan pengalaman) yang diamati dan dianalisis dengan melihat kecenderugan distribusinya. Hasil penelitian menunjukan bahwa faktor pendidikan tinggi Sarjana (S1) cenderung lebih baik daripada yang bukan Sarjana dalam pelaksanaan tugas. Dilain hal pengalaman lama bertugas dan yang belum lama bertugas menunjukan kecenderungan yang relatif belum lama bertugas $(<20$ tahun $)$ lebih baik daripada yang sudah lama bertugas $(>20$ tahun). Sebagai kesimpulan bahwa karakteristik sosial ekonomi berdasarkan latar belakang pendidikan berhubungan dengan pelaksanaan tugas.
\end{abstract}

\footnotetext{
*Korespondensi (corresponding Author)

Email: bfjsondakh@yahoo.com
}

Semakin tinggi pendidikan penyuluh semakin baik pelaksanaan tugasnya.

Kata kunci: Karakteristik, Sosial Ekonomi, Pelaksanaan Tugas, Penyuluh

ABSTRACT
ANALYSIS OF
ECONOMIC CHARACTERISTICS
OF EDUCATOR
WXTEHS
MINAHASA. Extension workers has a
strategic role in improving the welfare
of farmers / ranchers. One of the factors
that influence the success of the
extension duties is the state socio-
economic background or socio-
economic characteristics of each
extension. However, the extent of the relationship between socioeconomic characteristics with the implementation of the extension in Minahasa unknown. Based on these problems, the purpose of this study was to determine the relationship of these characteristics with the execution of tasks with good extension. This study uses survey data collection on respondents extension and analyzed descriptively. The collected data are presented in tables cross between variables (education and experience) were observed and analyzed by looking at the distribution Trends. The results showed that the factor of higher education Bachelor (S1) tend to be better than not on the Bachelor in execution of duty. On the other hand experience of long-serving and who have served a long time showed relatively recent trend duty ( $<20$ years) is better than the longtime ( $>20$ years). As a conclusion that the social and economic characteristics based on the 
educational background related to the implementation of the tasks. The higher the education the better performance of its duties educator.

Keywords: Characteristics , Social Economy, Duties , Extension

\section{PENDAHULUAN}

Dalam rangka membangun pertanian dan peternakan yang baik diperlukan pelaku pembangunan yang memiliki kemampuan dalam memanfaatkan segala sumber daya secara optimal. Perwujudan pertanian dan peternakan yang tangguh diperlukan aparat yang tangguh di bidang pengaturan, pelayanan, dan penyuluhan yang sesuai dengan spesialisasi yang dibutuhkan (Soedijanto, 1996).

Penyuluhan diartikan sebagai proses pemebelajaran pelaku utama dan pelaku usaha agar mau dan mampu menolong dirinya dalam mengakses informasi, teknologi, permodalan, dan sumber lainnya sebagai upaya meningkatkan produktivitas, efisiensi usaha pendapatan dan kesejahteraan (Wangke, 2012).

Tujuan penyuluhan adalah mengubah perilaku petani dan keluarganya yaitu mengubah pengetahuan, sikap, serta ketrampilannya. Perubahan ini akan menjadi pintu gerbang terjadinya penghayatan dan penerapan dari inovasi yang disuluhkan atau yang menjadi misi penyuluh. Penyuluhan berasaskan partisipatif yaitu penyelenggaraan penyuluhan yang melibatkan secara aktif pelaku utama dan pelaku usaha dan penyuluh (Damanik, 2014).

Menurut Nababan (2013), faktor yang mempengaruhi keberhasilan penyuluhan adalah Karakteristik penyuluh yaitu umur, pendidikan, lama bekerja frekuensi kunjungan, jumlah tanggungan, fasilitas yang dimiliki untuk menyuluh, serta tingkat pendapatan adalah bagian yang dapat diukur dari penyuluh

Karakteristik adalah mengacu kepada karakter dan gaya hidup seseorang serta nilai-nilai yang berkembang secara teratur sehingga tingkah laku menjadi lebih konsisten dan mudah di perhatikan. Selain itu, karakteristik merupakan ciri atau karateristik yang secara alamiah melekat pada diri seseorang yang meliputi umur, jenis kelamin, ras/suku, pengetahuan, agama/ kepercayaan dan sebagainya (Viforit, 2014). Kinerja penyuluh dipengaruhi juga dengan karakteristik yaitu umur, pendidikan, pengalaman, jumlah tanggungan keluarga dan pendapatan (Janis, 2014). 
Berdasarkan data pra survey khusus kabupaten Minahasa penyuluh yang ada mempunyai jabatan yang fungsional artinya mereka bisa mencakup sektor pertanian, peternakan, perkebunan, dan kehutanan. Kondisi ini menunjukan penyuluh-penyuluh yang ada di Kabupaten Minahasa dapat memberikan penyuluhan pada sektor pertanian secara luas.

Kelompok tani berjumlah 1.257 kelompok tani, keadaan gabungan kelompok tani di kabupaten minahasa yang tersebar di 25 kecamatan berjumlah 127 Gapoktan, 117 Gapoktan melaksanakan kegiatan dengan penguatan modal dari Pengembangan Usaha Agribisnis Pedesaan (PUAP) dan 10 Gapoktan melaksanakan kegiatan program Lembaga Distribusi Pangan Masyarakat (LDPM), (BP4K Kab. Minahasa)

Permasalahannya, sejauh mana hubungan antara karakteristik sosial ekonomi penyuluh dengan pelaksanaan penyuluhan belum diketahui. Tujuannya untuk mengetahui pelaksanaan penyuluhan di Kabupaten Minahasa dengan baik.

\section{METODE PENELITIAN}

Penelitian ini dilaksanakan di Kabupaten Minahasa, yaitu mulai bulan
Agustus tahun 2015 sampai dengan bulan November tahun 2015. Metode pengumpulan data menggunakan metode survey. Penentuan sampel dilakukan secara purposive sampling yaitu dengan sengaja memilih daerahdaerah di Kabupaten Minahasa. Populasi dalam penelitian ini adalah penyuluh peternakan lapangan. Data yang dikumpulkan yaitu data primer dan data sekunder. Data primer diperoleh dari penyuluh yang ada di Kabupaten Minahasa. Dalam penelitian ini yang menjadi responden adalah petugas penyuluh dan kelompok tani. Responden ini yang diminta memberikan keterangan tentang sesuatu fakta/pendapat. Keterangan tersebut didapat pada saat wawancara dengan menjawab pertanyaan yang telah disiapkan dalam bentuk kuesioner atau daftar pertanyaan.

Metode analisis yang digunakan yaitu analisis deskriptif secara verbal dengan tahap pertama melakukan pemeriksaan data, dimana pada kegiatan ini dilakukan setelah melakukan wawancara (mengisi daftar pertanyaan). Selanjutnya tahap pengolahan data, dimana dalam tahap ini data yang telah terkumpul diolah untuk memperoleh tabulasi. Metode deskriptif dapat diartikan sebagai prosedur pemecahan 
masalah yang diselidiki dengan mendeskripsikan keadaan subjek/objek penelitian berdasarkan fakta-fakta yang tampak atau sebagaimana adanya (Nawawi, 1995).

\section{HASIL DAN PEMBAHASAN}

\section{Gambaran Umum Lokasi Penelitian}

Minahasa adalah salah satu kabupaten di Sulawesi Utara, letak diujung utara pulau Sulawesi. Ibukota Kabupaten Minahasa adalah Tondano, berjarak sekitar $35 \mathrm{~km}$ dari Manado, ibukota provinsi Sulawesi Utara. Luas wilayah Kabupaten Minahasa adalah $1.029,82 \mathrm{~km}^{2}$, yang terdiri dari 25 Kecamatan masing-masing kecamatan Langowan Timur, Langowan Barat, Langowan Selatan, Langowan Utara, Tompaso, Tompaso Barat, Kawangkoan, Kawangkoan Utara, Kawangkoan Barat, Sonder, Tombariri, Tombariri Timur, Pineleng, Mandolang, Tombulu, Tondano Barat, Tondano Selatan, Remboken, Kakas, Kakas Barat, Lembean Timur, Eris, Kombi, Tondano Timur, Tondano Utara.

Adapun batas kabupaten adalah sebagai berikut:

- Sebelah utara berbatasan dengan Laut Sulawesi, Kota Manado.

- Sebelah Timur berbatasan dengan Laut Maluku.
- Sebelah Selatan berbatasan dengan Kabupaten Minahasa Selatan dan Kabupaten Minahasa Tenggara.

- Sebelah Barat berbatasan dengan kota tomohon, kabupaten Minahasa Selatan dan Laut Sulawesi

\section{Karakteristik Sosial Ekonomi Penyuluh}

Seluruh responden yang berjumlah 30 orang pada penelitian ini adalah penyuluh yang mempunyai wilayah kerja di Kabupaten Minahasa. Penyuluh-penyuluh ini tersebar di seluruh BP3K di setiap kecamatan yang ada di Kabupaten Minahasa. Data latar belakang sosial ekonomi penyuluh dalam penelitian ini yaitu umur, pendidikan, pengalaman, tanggungan keluarga, dan penghasilan. Latar belakang sosial ekonomi penyuluh dapat dilihat pada tabel 1 . 
Tabel 1. Distribusi responden berdasarkan latar belakang sosial ekonomi penyuluh

\begin{tabular}{|c|c|c|c|}
\hline No. & $\begin{array}{l}\text { Karakteristik sosial ekonomi } \\
\text { Penyuluh }\end{array}$ & $\begin{array}{l}\text { Jumlah } \\
\text { (orang) }\end{array}$ & $\begin{array}{l}\text { Presentase } \\
(\%)\end{array}$ \\
\hline \multirow[t]{4}{*}{1} & Umur & & \\
\hline & 38-44 tahun & 4 & 13.4 \\
\hline & $44-50$ & 7 & 23.3 \\
\hline & $50-56$ & 19 & 63.3 \\
\hline \multirow[t]{4}{*}{2} & Pendidikan & & \\
\hline & S1 & 20 & 66.7 \\
\hline & D3 & 2 & 6.6 \\
\hline & SPMA & 8 & 26.7 \\
\hline \multirow[t]{4}{*}{3} & Pengalaman menyuluh & & \\
\hline & 8-16 tahun & 7 & 23.3 \\
\hline & 17-24 tahun & 11 & 36.7 \\
\hline & 25-33 tahun & 12 & 40 \\
\hline \multirow[t]{4}{*}{4} & Tanggungan keluarga & & \\
\hline & $<3$ orang & 13 & 43.3 \\
\hline & 4 orang & 14 & 46.7 \\
\hline & 5 orang & 3 & 10 \\
\hline \multirow[t]{4}{*}{5} & Pendapatan & & \\
\hline & $4.000 .000-4.850 .000$ & 20 & 66.6 \\
\hline & $3.100 .000-3.950 .000$ & 2 & 6.7 \\
\hline & $2.150 .000-3.000 .000$ & 8 & 26.7 \\
\hline
\end{tabular}

Keterangan: $* \mathrm{n}=30$

\section{Umur}

Kisaran umur penyuluh dalam penelitian ini adalah 38-56 tahun, hampir keseluruhan penyuluh berumur produktif dalam hal pengalaman, sudah mampu bekerja dan siap untuk menjalankan tugas penyuluhan. Hasil penelitian yang diperoleh umur penyuluh pada umumya berkisar 38-44 tahun sebanyak 4 orang. Penyuluh yang berumur 45-50 tahun sebanyak 13 orang dan penyuluh yang berumur 51-56 tahun sebanyak 13 orang. Umur akan mempengaruhi kemampuan fisik bekerja, cara berfikir dan kinerja penyuluh dalam tugasnya di lapangan.

\section{Pendidikan}

Pendidikan formal adalah jalur pendidikan terstruktur dan berjenjang yang ditempuh penyuluh berstatus negeri maupun swasta. Sebaran tingkat pendidikan penyuluh adalah dari SPMA sampai perguruan tinggi. Tingkat pendidikan penyuluh berkaitan dengan ilmu pengetahuan serta pola pikir dalam menjalankan tugasnya sebagai penyuluh. Penyuluh yang ada di kabupaten Minahasa $66,7 \%$ sudah memiliki gelar sarjana, bisa dikatakan para penyuluh sudah memiliki tingkat pendidikan yang baik. Menurut data diatas penyuluh yang tamatan SPMA 
berjumlah 8 orang, penyuluh yang tamatan D3 berjumlah 2 orang, dan peyuluh yang tamatan $\mathrm{S} 1$ berjumlah 20 orang.

\section{Pengalaman menjadi Penyuluh}

Pengalaman menjadi penyuluh mempengaruhi pengetahuan atau kemampuan dalam menjalankan tugas sebagai penyuluh. Semakin tinggi pengalaman penyuluh semakin banyak hal yang diketahui penyuluh itu. Orangorang yang lama bekerja pada suatu pekerjaan akan lebih produktif daripada mereka yang senioritasnya lebih rendah. Pengalaman penyuluh dapat dilihat juga dari pengalaman penyuluh dalam mengikuti diklat dan pendidikan lain yang berhubungan dengan penyuluhan. Penyuluh yang mempunyai pengalaman menyuluh 8-16 tahun berjumlah 7 orang, penyuluh yang mempunyai pengalaman 17-24 tahun berjumlah 11 orang, dan penyuluh yang mempunyai pengalaman 25-33 tahun berjumlah 12 orang.

\section{Jumlah Tanggungan Keluarga}

Jumlah tanggungan keluarga adalah jumlah anggota keluarga yang dinafkahi oleh penyuluh dan sekaligus menjadi beban bagi penyuluh tersebut. Semakin besar jumlah anggota keluarga akan semakin besar pula tuntutan kebutuhan keuangan rumah tangga. Kegagalan penyuluh dalam penyuluhan akan berpengaruh dalam kehidupan keluarga. Penyuluh yang mempunyai tanggungan >3 berjumlah 13 orang, penyuluh yang mempunyai tanggungan 4 berjumlah 14 orang, dan penyuluh yang mempunyai tanggungan 5 berjumlah 3 orang.

\section{Pendapatan}

Pendapatan merupakan penghasilan penyuluh yang di terima dari gaji dan penghasilan lainnya. Pendapatan penyuluh umumnya diterima dari gaji yang diberikan pemerintah sebagai upah atas apa yang dikerjakan penyuluh tersebut. Pendapatan penyuluh berfungsi untuk menafkahi anggota keluarga penyuluh dan untuk memenuhi kebutuhan rumah tangga seperti makanan, pakaian, dan perumahan. Hasil yang diperoleh di lapangan penyuluh yang mempunyai pendapatan 2-3 juta berjumlah 8 orang, penyuluh yang mempunyai pendapatan 3-4 juta berjumlah 2 orang, dan penyuluh yang mempunyai pendapatan 4-5 juta berjumlah 20 orang.

\begin{tabular}{|c|c|}
\hline Analisis & Karakteristik \\
\hline Ekonomi & Dengan \\
\hline
\end{tabular}


Tabel 2. Analisis antara Pendidikan dengan Tugas Penyuluh

\begin{tabular}{|c|c|c|c|c|c|c|}
\hline \multirow[t]{2}{*}{ No. } & \multirow[t]{2}{*}{ Tugas-tugas penyuluh } & \multirow[b]{2}{*}{ Pengukuran } & \multicolumn{4}{|c|}{ Pendidikan } \\
\hline & & & $\geq \mathrm{S} 1$ & $\%$ & $<\mathrm{S} 1$ & $\%$ \\
\hline \multirow[t]{3}{*}{1.} & \multirow[t]{3}{*}{ Kunjungan penyuluh: } & - Sering & 17 & 85 & 8 & 80 \\
\hline & & - Jarang & 3 & 15 & 2 & 20 \\
\hline & & - Tidak pernah & - & - & - & - \\
\hline \multirow[t]{3}{*}{2.} & \multirow[t]{3}{*}{ Frekuensi penyuluhan } & - 3 kali/minggu & 12 & 60 & 3 & 30 \\
\hline & & - 2 kali/minggu & 6 & 30 & 6 & 60 \\
\hline & & - $1 \mathrm{kali} / \mathrm{minggu}$ & 2 & 10 & 1 & 10 \\
\hline \multirow[t]{3}{*}{3.} & \multirow[t]{3}{*}{ Kehadiran peserta } & $-80 \%-100 \%$ & 8 & 40 & 2 & 20 \\
\hline & & $-50 \%-70 \%$ & 10 & 50 & 6 & 60 \\
\hline & & $-20 \%-40 \%$ & 2 & 10 & 2 & 20 \\
\hline \multirow[t]{3}{*}{4.} & \multirow[t]{3}{*}{ Komunikasi penyuluhan } & - Baik & 15 & 75 & 5 & 50 \\
\hline & & - Cukup & 5 & 25 & 5 & 50 \\
\hline & & - Kurang & - & - & - & - \\
\hline \multirow[t]{3}{*}{5.} & \multirow[t]{3}{*}{ Kesesuaian materi } & - Selalu & 18 & 80 & 10 & 100 \\
\hline & & - Kadang-kadang & 2 & 20 & - & - \\
\hline & & - Tidak pernah & - & - & - & - \\
\hline \multirow[t]{3}{*}{6.} & \multirow{3}{*}{ Kesesuaian program } & - Selalu & 20 & 95 & 7 & 78 \\
\hline & & - Kadang-kadang & 1 & 5 & 2 & 22 \\
\hline & & - Tidak pernah & - & - & - & - \\
\hline \multirow[t]{3}{*}{7.} & \multirow[t]{3}{*}{ Materi yang diberikan } & - Sangat membantu & 19 & 95 & 9 & 80 \\
\hline & & - Cukup membantu & 1 & 5 & 1 & 20 \\
\hline & & - Kurang membantu & - & - & - & - \\
\hline \multirow[t]{3}{*}{8.} & \multirow[t]{3}{*}{ Perubahan perilaku } & - Selalu & 9 & 47 & 9 & 81 \\
\hline & & - Kadang-kadang & 10 & 53 & 2 & 19 \\
\hline & & - Tidak pernah & - & - & - & - \\
\hline \multirow[t]{3}{*}{9.} & \multirow[t]{3}{*}{ Pemecahan masalah } & - Selalu & 18 & 94 & 10 & 91 \\
\hline & & - Kadang-kadang & 1 & 6 & 1 & 9 \\
\hline & & - Tidak pernah & - & - & - & - \\
\hline \multirow[t]{3}{*}{10.} & \multirow{3}{*}{$\begin{array}{l}\text { Metode penyuluhan } \\
\text { perorangan }\end{array}$} & - Selalu & 5 & 25 & 2 & 20 \\
\hline & & - Kadang-kadang & 15 & 75 & 8 & 80 \\
\hline & & - Tidak pernah & - & - & - & - \\
\hline \multirow[t]{3}{*}{11} & Metode penyuluhan & - Selalu & 20 & 100 & 10 & 100 \\
\hline & \multirow[t]{2}{*}{ kelompok } & - Kadang-kadang & - & - & - & - \\
\hline & & - Tidak pernah & - & - & - & - \\
\hline
\end{tabular}

Tabel 2 menunjukkan hubungan antara karakteristik sosial ekonomi dengan pelaksanaan penyuluhan yang menunjukan bahwa adanya persentase yang tinggi jika penyuluh berpendidikan Sarjana (S1) daripada pendidikan yang bukan Sarjana. Hal ini menunjukan bahwa pendidikan yang tinggi mempunyai hubungan dengan pelaksanaan tugas penyuluh, sedangkan pendidikan yang rendah tidak mempunyai hubungan dengan pelaksanaan tugas. Artinya, latar belakang pendidikan berhubungan dengan pelaksanaan tugas penyuluh di Kabupaten Minahasa. Kondisi ini berbeda dengan pendapat Khalida (2009) yang menyatakan pendidikan tidak ada hubungan dengan pelaksanaan tugas penyuluh. 
Tabel 3. Analisis antara Pengalaman dengan Tugas Penyuluh

\begin{tabular}{|c|c|c|c|c|c|c|}
\hline \multirow[t]{2}{*}{ No. } & \multirow[t]{2}{*}{ Tugas-tugas penyuluh } & \multirow[b]{2}{*}{ Pengukuran } & \multicolumn{4}{|c|}{ Pengalaman } \\
\hline & & & $>20$ & $\%$ & $<20$ & $\%$ \\
\hline \multirow[t]{3}{*}{1.} & Kunjungan penyuluh & - Sering & 16 & 89 & 10 & 83 \\
\hline & & - Jarang & 2 & 11 & 2 & 17 \\
\hline & & - Tidak pernah & - & - & - & - \\
\hline \multirow[t]{3}{*}{2.} & Frekuensi penyuluhan & - 3 kali/minggu & 9 & 50 & 6 & 50 \\
\hline & & - 2 kali/minggu & 7 & 39 & 5 & 41 \\
\hline & & - 1 kali/minggu & 2 & 11 & 1 & 9 \\
\hline \multirow[t]{3}{*}{3.} & Kehadiran peserta & $-80 \%-100 \%$ & 7 & 39 & 3 & 25 \\
\hline & & $-50 \%-70 \%$ & 9 & 50 & 6 & 50 \\
\hline & & $-20 \%-40 \%$ & 2 & 11 & 3 & 25 \\
\hline \multirow[t]{3}{*}{4.} & Komunikasi penyuluhan & - Baik & 12 & 67 & 9 & 75 \\
\hline & & - Cukup & 6 & 33 & 3 & 25 \\
\hline & & - Kurang & - & - & - & - \\
\hline \multirow[t]{3}{*}{5.} & Kesesuaian materi & - Selalu & 15 & 83 & 11 & 97 \\
\hline & & - Kadang-kadang & 3 & 17 & 1 & 3 \\
\hline & & - Tidak pernah & - & - & - & - \\
\hline \multirow[t]{3}{*}{6.} & Kesesuaian program & - Selalu & 16 & 89 & 11 & 91 \\
\hline & & - Kadang-kadang & 2 & 11 & 1 & 9 \\
\hline & & - Tidak pernah & - & - & - & - \\
\hline \multirow[t]{3}{*}{7.} & Materiyang diberikan & - Sangat membantu & 16 & 89 & 11 & 91 \\
\hline & & - Cukup membantu & 2 & 11 & 1 & 9 \\
\hline & & - Kurang membantu & - & - & - & - \\
\hline \multirow[t]{3}{*}{8.} & Perubahan perilaku & - Selalu & 9 & 47 & 9 & 81 \\
\hline & & - Kadang-kadang & 10 & 53 & 2 & 19 \\
\hline & & - Tidak pernah & - & - & - & - \\
\hline \multirow[t]{3}{*}{9.} & Pemecahan masalah & - Selalu & 5 & 27 & 2 & 17 \\
\hline & & - Kadang-kadang & 13 & 73 & 10 & 83 \\
\hline & & - Tidak pernah & - & - & - & - \\
\hline \multirow[t]{3}{*}{10.} & Metode penyuluhan & - Selalu & 3 & 17 & 4 & 33 \\
\hline & perorangan & - Kadang-kadang & 15 & 73 & 8 & 67 \\
\hline & & - Tidak pernah & - & - & - & - \\
\hline \multirow[t]{3}{*}{11} & Metode penyuluhan & - Selalu & 13 & 100 & 17 & 100 \\
\hline & kelompok & - Kadang-kadang & - & - & - & - \\
\hline & & - Tidak pernah & - & - & - & - \\
\hline
\end{tabular}

Data tabel 3 menunujukan bahwa persentase yang tinggi cenderung pada pengalaman yang belum lama $(<20$ tahun) daripada pengalaman lama bertugas (>20 tahun). Hal ini menunjukan bahwa pengalaman yang tinggi belum tentu dapat melaksanakan tugas dengan baik, sedangkan pengalaman yang rendah belum tentu tidak dapat menjalankan tugas dengan baik. Artinya pengalaman tidak mempunyai hubungan dengan pelaksanaan tugas penyuluh. Hasil penelitian ini berbeda dengan pendapat Khalida (2009) yang menyatakan pengalaman ada hubungannya dengan pelaksanaan tugas penyuluh.

\section{KESIMPULAN}

Berdasarkan hasil dan pembahasan, maka dapat diambil kesimpulan bahwa karakteristik sosial ekonomi berdasarkan latar belakang pendidikan berhubungan dengan 
pelaksanaan tugas penyuluh. Semakin tinggi pendidikan penyuluh maka semakin baik pelaksanaan tugasnya.

\section{DAFTAR PUSTAKA}

Badan Pelaksana Penyuluhan Pertanian,

Perikanan, dan Kehutanan (BP4K). Programa Penyuluhan Pertanian. (Minahasa : 2014)

Damanik, D. P. 2014. Hubungan karakteristik petani peternak sapi dengan kinerja penyuluhan (kasus: desa ara condong, kecamatan stabat kabupaten langkat. Jurnal agribisnis Vol 3. No. 5 : $34-43$

Janis, R. 2014. Kinerja Penyuluh Pertanian Di Wilayah Kerja Badan Pelaksana Penyuluh Pertanian Perikanan Dan Kehutanan (BP4K) Kabupaten Kepulauan Sangihe. Jurnal cocos Vol.4 No.4 : 20-42

Khalida, L. 2009. Hubungan Karakteristik Sosial Ekonomi Penyuluh dengan Pelaksanaan Tugas Pokok Penyuluh Pertanian: Studi Kasus BPP Medan Krio Kecamatan Sunggal Kabupaten Deli Serdang. Universitas Sumatera Utara. Medan.
Nababan, I. M. 2013. Hubungan karakteristik penyuluh pertanian pns terhadap keberhasilan penyuluhan (kasus: kecamatan sunggal dan kutalimbaru kabupaten deli serdang). Jurnal agribisnis Vol 2. No $10: 236$ 252

Nawawi. 1995. Dikata Evaluasi Penyuluhan Pertanian APP

Soedijanto. 1996. Administrasi Penyuluhan Pertanian. Jakarta: Universitas Terbuka, Departemen Pendidikan dan Kebudayaan.

Viforit, A. 2014. Pengaruh Karakteristik Sosial Ekonomi Penyuluh Terhadap Tingkat Keberhasilan Pelaksanaan Tugas Pokok Penyuluh Pertanian (di BPP Pematang Sijonam, Kabupaten Serdang Bedagai). Jurnal agribisnis Vol 3 No. 5 : 102-118 Wangke, W. M. 2012. Hubungan Karakteristik Sosial Ekonomi Petani Dengan Ke-Ikutsertaan Dalam Penyuluhan Pertanian Di Desa Kamanga Kecamatan Tompaso Kabupaten Minahasa. Jurnal zootek Vol 11. No 1 : 5863 